Pacific Journal of Mathematics

THE EXPONENTIAL ANALOGUE OF A GENERALIZED 


\title{
THE EXPONENTIAL ANALOGUE OF A GENERALIZED WEIERSTRASS SERIES
}

\author{
George J. Kertz and Francis Regan
}

The generalized Weierstrass series

$$
\sum_{n=1}^{\infty} a_{n} \frac{z^{n}}{1+z^{2 n}}
$$

has as its exponential analogue

$$
\sum_{n=1}^{\infty} a_{n} \frac{e^{-\lambda_{n} z}}{1+e^{-2 \lambda_{n} z}}
$$

where $\left\{a_{n}\right\}$ is a sequence of complex-valued constants and $\left\{\lambda_{n}\right\}$ is any real-valued strictly monotone increasing unbounded sequence.

In this paper the $\lambda_{n}$ will be chosen to be $\ln n$. Then the above series becomes

$$
A(\boldsymbol{z})=\sum_{n=1}^{\infty} a_{n} \frac{n^{-z}}{1+n^{-2 z}},
$$

hereafter called simply the $A$-series. In its region of absolute convergence an $A$-series can be expressed as a Dirichlet series; conversely, a Dirichlet series can be represented by an $A$ series. Under restrictions on the sequence $\left\{a_{n}\right\}$, the imaginary axis becomes a natural boundary of the function represented by the $A$-series.

Since $A(z)=A(-z)$, only values of $z=x+i y, x>0$, will be considered. Similar results hold in (1) for corresponding values of $-z$. Hereafter, unless otherwise indicated, all summations will be understood to range from $n=1$ to $\infty$.

2. Convergence of the $A$-series. The following theorems on convergence are stated without proof.

THeOREM 1. (A) If $\sum a_{n}$ diverges, the A-series converges and diverges for all points $z=x+i y, x>0$, with the associated Dirichlet series $\sum a_{n} n^{-z}$.

(B) If $\sum a_{n}$ converges, the A-series converges for all points $z=$ $x+i y, x>0$.

Theorem 1 remains true if ordinary convergence and divergence are replaced by absolute convergence and divergence throughout the statement of the theorem. 
THeOREM 2. If the A-series converges at any point $z_{0}=x_{0}+i y_{0}$, $x_{0}>0$, then the A-series converges uniformly over an angular region with vertex at $z_{0}$ defined by $\left|\arg \left(z-z_{0}\right)\right| \leqq \omega, 0 \leqq \omega<\pi / 2$.

THeORem 3. If the A-series converges absolutely at a point $z_{0}=$ $x_{0}+i y_{0}, x_{0}>0$, then the A-series converges absolutely uniformly over the half plane comprising the points $z=x+i y, x>x_{0}$.

3.Expansion of the $A$-series and inversion of a Dirichlet series. Expanding each term of the $A$-series and rewriting result in the doubly infinite array

$$
\frac{a_{1}}{2}+\sum_{n=2}^{\infty} \sum_{c=J}^{\infty}(-1)^{c} a_{n}\left(n^{2 c+1}\right)^{-z}
$$

which when summed according to increasing values of $n^{2 c+1}, n=$ $2,3,4, \cdots ; c=0,1,2, \cdots$ can be expressed as the single series

$$
\frac{a_{1}}{2}+\sum_{k=2}^{\infty} b_{k} k^{-z}=\sum_{k=1}^{\infty} b_{k} k^{-z}
$$

where $b_{1}=a_{1} / 2$. There remains to determine $b_{k}$ for $k>1$.

In (2) above, $(-1)^{c} a_{n}$ is a coefficient of $k^{-z}, k>1$, if and only if $n^{2 c+1}=k$, or equivalently $\left.c=(1 / 2)\{(\ln k / \ln n)-1)\right\}$. The coefficient $b_{k}$ will then be the sum

$$
b_{k}=\sum_{n^{d^{\prime}}=k}(-1)^{1 / 2\{(\ln k / \ln n)-1\}} a_{n}
$$

where the summation extends over all $n$ such that for some odd natural number $d^{\prime}, n^{d^{\prime}}=k$. Hereafter, a primed letter, e.g. $d^{\prime}$, will be used to indicate only odd natural numbers.

Assume now that the $A$-series converges absolutely at a point $z_{0}=x_{0}+i y_{0}, x_{0}>0$, and consider again the double array (2) above, taking the absolute values of the individual terms. The $n$th row converges to $\left|a_{n}\right|\left(n^{-x_{0}} / 1-n^{-2 x_{0}}\right)$ and the sum of the "row-sums" is

$$
\sum\left|a_{n}\right| \frac{n^{-x_{0}}}{1-n^{-2 x_{0}}}
$$

which can also be shown to be convergent by comparison with the assumed convergent series. Consequently the elements of the double array can be rewritten in any order without affecting convergence; that is, the Dirichlet series (3) converges to the same value as the $A$-series. Hence

Theorem 4. In its region of absolute convergence an A-series 


$$
\sum a_{n} \frac{n^{-z}}{1+n^{-2 z}}
$$

can be represented by a Dirichlet series $\sum_{k=1}^{\infty} b_{k} k^{-z}$, where $b_{1}=a_{1} / 2$ and for $k>1$

$$
b_{k}=\sum_{n^{d^{\prime}=k}}(-1)^{1 / 2\{(\ln k / \ln n)-1\}} a_{n}
$$

Conversely, given the coefficients $b_{1}, b_{2}, \cdots$ of a Dirichlet series, the equations

$$
b_{1}=a_{1} / 2, b_{k}=\sum_{n^{\prime}=k}(-1)^{1 / 2\{(\ln k / \ln n)-1\}} a_{n}
$$

determine the $a_{n}$ uniquely. This is the case since, in the last sum, the largest value of $n$ occurs when $d^{\prime}=1$. We have therefore

TheOREM 5. A given Dirichlet series $\sum_{k=1}^{\infty} b_{k} k^{-z}$ can be represented by an A-series.

The value of $a_{n}, n>1$, can be calculated by

$$
a_{n}=\sum_{n=k^{f^{\prime}}} J\left(\frac{\ln n}{\ln k}\right) b_{k}
$$

where $J(d)$ is defined recursively by

$$
\sum_{k=d d^{\prime}}(-1)^{\left\{\left(d^{\prime}-1 / 2\right)\right\}} J(d)=\left\{\begin{array}{l}
1 \text { for } k=1 \\
0 \text { for } k>1
\end{array}\right.
$$

the summation being taken over all positive integral divisors, $d$, of $k$ whose corresponding quotients, $d^{\prime}$, are odd.

4. Existence of a natural boundary. We first determine the behavior of the function represented by an $A$-series as the variable approaches the axis of imaginaries along lines parallel to the axis of reals. This is established by the following theorem.

THEOREM 6. Let $z=x+i y^{\prime}$, where $x>0$ and $y^{\prime}$ is a fixed element of the set $\left(\pi k^{\prime} / 2(\ln k): k^{\prime}=(2 r+1), r=0, \pm 1, \pm 2, \cdots ; k=\right.$ $2,3,4, \cdots)$. Let the coefficients of the A-series be so chosen that

$$
\sum\left|a_{n}\right| n^{\left|k^{\prime}\right|}<\infty
$$

Then

$$
\lim _{x \rightarrow 0} x \sum a_{n} \frac{n^{-z}}{1+n^{-2 z}}=\frac{1}{\ln k} \sum_{r=1}^{\infty} a_{r}^{*} \frac{1}{2(2 r-1)}
$$


where $a_{r}^{*}=(-i)^{(2 r-1) k^{\prime}} a_{k^{(2 r-1)}}$.

As a consequence of the hypothesis, $\sum\left|a_{n}\right|$ also converges, and by the comment following Theorem 1 the $A$-series converges absolutely over the half plane $x>0$. The $A$-series may therefore be written as the sum of the two series indicated below.

Consider the subset of terms of the $A$-series for which $n=k^{v^{\prime}}$, $k$ determined by the choice of $y^{\prime}$, and $v^{\prime}$ an odd natural number. Indicate the summation of these terms by $\sum_{1}$ and the summation of all remaining terms by $\Sigma_{2}$. A typical term of $\Sigma_{1}$ is

$$
\begin{aligned}
a_{n} \frac{n^{-z}}{1+n^{-2 z}} & =a_{k^{v^{\prime}}} \frac{e^{-v^{\prime}(\ln k)\left(x+i y^{\prime}\right)}}{1+e^{-2 v^{\prime}(\ln k)\left(x^{+} i y^{\prime}\right)}} \\
& =a_{k^{\prime}} \frac{(-i) \sin \left(v^{\prime} \pi k^{\prime} / 2\right) e^{-v^{\prime}(\ln k) x}}{1-e^{-2 v^{\prime}(\ln k) x}} .
\end{aligned}
$$

Replacing $v^{\prime}$ by its equal from the set $\{(2 r-1): r=1,2,3, \cdots\}$, and making the substitutions $w=e^{-(\ln k) x}$ and $a_{r}^{*}=(-i)^{(2 r-1) k^{\prime}} a_{k^{(2 r-1)}}$ permit $\sum_{1}$ to be written

$$
\sum_{r=1}^{\infty} a_{r}^{*} \frac{w^{(2 r-1)}}{1-w^{2(2 r-1)}}
$$

Consider now

$$
\begin{aligned}
& \lim _{w \rightarrow 1^{-}}\left\{(1-w) \sum_{r=1}^{\infty} a_{r}^{*} \frac{w^{(2 r-1)}}{1-w^{2(2 r-1)}}\right\} \\
& =\lim _{w \rightarrow 1^{-}} \frac{(1-w)}{1-w^{2}} \lim _{w \rightarrow 1^{-}}\left\{\left(1-w^{2}\right) \sum_{r=1}^{\infty} a_{r}^{*} \frac{w^{(2 r-1)}}{1-w^{2(2 r-1)}}\right\} \\
& =\frac{1}{2} \lim _{w \rightarrow 1^{-}}\left\{\left(1-w^{2}\right) \sum_{r=1}^{\infty} a_{r}^{*} \frac{w^{(2 r-1)}}{1-w^{2(2 r-1)}}\right\} \text {. }
\end{aligned}
$$

By another substitution, $w^{2}=t$, this last limit becomes

$$
\begin{aligned}
& \frac{1}{2} \lim _{t \rightarrow 1^{-}}\left\{(1-t) \sum_{r=1}^{\infty} a_{r}^{*} \frac{t^{(2 r-1) / 2}}{1-t^{(2 r-1)}}\right\} \\
& \quad=\lim _{t \rightarrow 1^{-}} \sum_{r=1}^{\infty} \frac{a_{r}^{*}}{2(2 r-1)} \cdot \frac{(2 r-1) t^{(2 r-1) / 2}}{1+t+t^{2}+\cdots+t^{2(r-1)}} .
\end{aligned}
$$

The series in this last expression is uniformly convergent for $0 \leqq t \leqq 1$ so that this last limit can be rewritten

$$
\begin{aligned}
\sum_{r=1}^{\infty} \lim _{t \rightarrow 1^{-}}\left\{\frac{a_{r}^{*}}{2(2 r-1)} \cdot \frac{(2 r-1) t^{(2 r-1) / 2}}{1+t+t^{2}+\cdots+t^{2(r-1)}}\right. \\
=\sum_{r=1}^{\infty} \frac{a_{r}^{*}}{2(2 r-1)} ;
\end{aligned}
$$

that is, the limit (4) has the value (5). Replacing $w$ in (4) by its 
equal yields

$$
\lim _{x \rightarrow 0^{+}}\left\{\left(1-k^{-x}\right) \Sigma_{1} a_{n} \frac{n^{-z}}{1+n^{-2 z}}\right\}=\sum_{r=1}^{\infty} \frac{a_{r}^{*}}{2(2 r-1)}
$$

or

$$
\lim _{x \rightarrow 0^{+}}+\left\{x \Sigma_{1} a_{n} \frac{n^{-z}}{1+n^{-2 z}}\right\}=\frac{1}{\ln k} \sum_{r=1}^{\infty} \frac{a_{r}^{*}}{2(2 r-1)},
$$

There remains to show that $\Sigma_{2}$ is uniformly convergent in some interval $0 \leqq x \leqq N$, for then

$$
\lim _{x \rightarrow 0^{+}}\left\{x \Sigma_{2}\right\}=\Sigma_{2} \lim _{x \rightarrow 0^{+}}\left\{x a_{n} \frac{n^{-z}}{1+n^{-2 z}}\right\}=0 .
$$

In order to establish the desired uniform convergence we shall require the following

LEMMA. If $k^{\prime}$ is an odd integer, if $n$ and $k$ are natural numbers, $k$ greater than one, $n \neq k^{v^{\prime}}$ for an odd natural number $v^{\prime}$, and if $y_{0}=\pi / 2(\ln k)$, then for $x \geqq 0$

$$
\left|n^{-2 x}+e^{-2 y_{0} k^{\prime}(\ln n)}\right| \geqq C \ln \left(1+(1 / n)^{\left|k^{\prime \prime}\right|}\right)
$$

where $C=\min \left\{1, y_{0}\right\}$.

Proof. The set of points $S=\left\{z: z=n^{-2 x}+e^{i 2 y_{0}\left|k^{\prime}\right|(\ln n)}\right\}$ lie on a circle of radius one about the point $n^{-2 x} \leqq 1$, but does not contain the element $z=n^{-2 x}-1$. If $z \in S$ and $R(z) \geqq n^{-2 x}$, then

$$
|z| \geqq 1>\ln \left(1+(1 / n)^{\left|k^{\prime}\right|}\right) \text {. }
$$

Hence under the transformation $w=u+i v=z-n^{-2 x}, z \in S$, we can restrict our attention to points on the unit circle about the origin lying to the left of the axis of imaginaries.

If $\alpha$ denotes the point $-n^{-2 x}$ on the $u$-axis, $w$ is a point on the unit circle in the second quadrant, $\beta$ is the projection of $w$ on the $u$-axis and $\delta$ is the point $(-1,0)$, then $|z|=\overline{w \alpha} \geqq \overline{w \beta}$. The minor arc $\widehat{w \delta}=\theta<2 \sin \theta=2 \widehat{w \beta}$, where $\theta$ is the central angle subtending the arc $\widehat{w \delta}$; hence $|z| \geqq \widehat{w \delta} / 2$. Since $w$ lies above the $u$-axis, the arc $\widehat{w \delta}=\pi Q-2 y_{0} \ln \left(n^{\left|k^{\prime}\right|}\right)$ where $Q$ is the least positive integer such that $Q \pi \geqq 2 y_{0}\left(\ln n^{\left|k^{\prime}\right|}\right)$; that is, the least positive integer $Q$ such that $k^{Q}-1>n^{\left|k^{\prime}\right|}$, from which we get $Q(\ln k)-\ln n^{\left|k^{\prime}\right|} \geqq \ln \left(1+(1 / n)^{\left|k^{\prime}\right|}\right)$ and finally $\pi Q-2 y_{0}\left(\ln n^{\left|k^{\prime}\right|}\right) \geqq 2 y_{0} \ln \left(1+(1 / n)^{\left|k^{\prime}\right|}\right)$. We have then $|z| \geqq$ $\widehat{w \delta} / 2 \geqq y_{0} \ln \left(1+(1 / n)^{\left|k^{\prime}\right|}\right)$. A similar result holds if $w$ lies on the unit circle in the third quadrant; the lemma follows. 
To complete the proof of the theorem then, we note that

$$
\left|1+n^{-2 z}\right|=\left|n^{-2 x}+e^{-i 2 k^{\prime} y_{0}(\ln n)}\right|
$$

for all $z$ such that $R(z) \geqq 0$; hence for $0 \leqq x \leqq N$

$$
\begin{gathered}
\Sigma_{2}\left|a_{n} \frac{n^{-z}}{1+n^{-2 z}}\right| \leqq \Sigma_{2}\left|a_{n}\right| \frac{1}{\left|1+n^{-2 z}\right|} \\
=\Sigma_{2}\left|a_{n}\right| \frac{1}{\left|n^{-2 x}+e^{-i 2 k^{\prime} y_{0}(\ln n)}\right|}
\end{gathered}
$$

which by the lemma is less than or equal to

$$
\frac{1}{C} \Sigma_{2}\left|a_{n}\right| \frac{1}{\left|\ln \left(1+(1 / n)^{\mid k^{\prime}}\right)\right|} .
$$

This last series, convergent whenever $\Sigma\left|a_{n}\right| n^{\left|k^{\prime}\right|}$ is, becomes the dominant series for the Weierstrass $M$-test.

Theorem VI is the main result required for the natural boundary theorem which follows. A set of integers will be called dense if there is a positive number $l$ such that every interval of length $l$ contains an integer of the set.

THeOREM 7. If, to each positive integer $k$ of an infinite set, there corresponds a dense set of $k^{\prime}$ such that

$$
\Sigma\left|a_{n}\right| n^{\left|k^{\prime}\right|}<\infty \quad \text { and } \quad \sum_{r=1}^{\infty}(-1)^{(2 r-1) k^{\prime}} a_{k^{(2 r-1)}} \neq 0,
$$

then $x=0$ is a natural boundary of the function represented by the A-series.

It is sufficient to show that set of singularities $\left\{i \pi k^{\prime} / 2(\ln k)\right\}$, where for each $k, k^{\prime}$ assumes those values for which the hypothesis of Theorem 6 are fulfilled, is everywhere dense on the axis of imaginaries.

\section{REFERENCES}

1. G. Hardy and M. Riesz, The general theory of Dirichlet series, Vol. 18 of Cambridge Tracts in Mathematics and Mathematical Physics, Cambridge University Press, Cambridge, 1952.

2. E.S. Kennedy, Exponential analogues of the Lambert series, Amer. J. Math. LVIII (1941), 443-459.

3. L. Weierstrass, Zur functionentheorie, Monatsberichte der Berliner Akademie, (1880), 719-743.

Received October 4, 1965.

SAINT LOUIS UNIVERSITY 


\section{PACIFIC JOURNAL OF MATHEMATICS}

\section{EDITORS}

H. SAMELSON

Stanford University

Stanford, California

J. P. JANS

University of Washington

Seattle, Washington 98105

\section{J. DuGUNDJI}

University of Southern California

Los Angeles, California 90007

RICHARD ARENS

University of California

Los Angeles, California 90024

\section{ASSOCIATE EDITORS}

E. F. BECKENBACH
B. H. NEUMANN

F. WOLF

K. YoSIDA

\section{SUPPORTING INSTITUTIONS}

\author{
UNIVERSITY OF BRITISH COLUMBIA \\ CALIFORNIA INSTITUTE OF TECHNOLOGY \\ UNIVERSITY OF CALIFORNIA \\ MONTANA STATE UNIVERSITY \\ UNIVERSITY OF NEVADA \\ NEW MEXICO STATE UNIVERSITY \\ OREGON STATE UNIVERSITY \\ UNIVERSITY OF OREGON \\ OSAKA UNIVERSITY \\ UNIVERSITY OF SOUTHERN CALIFORNIA
}

\author{
STANFORD UNIVERSITY \\ UNIVERSITY OF TOKYO \\ UNIVERSITY OF UTAH \\ WASHINGTON STATE UNIVERSITY \\ UNIVERSITY OF WASHINGTON \\ AMERICAN MATHEMATICAL SOCIETY \\ CHEVRON RESEARCH CORPORATION \\ TRW SYSTEMS \\ NAVAL ORDNANCE TEST STATION
}

Mathematical papers intended for publication in the Pacific Journal of Mathematics should be typewritten (double spaced). The first paragraph or two must be capable of being used separately as a synopsis of the entire paper. It should not contain references to the bibliography. Manuscripts may be sent to any one of the four editors. All other communications to the editors should be addressed to the managing editor, Richard Arens at the University of California, Los Angeles, California 90024 .

50 reprints per author of each article are furnished free of charge; additional copies may be obtained at cost in multiples of 50 .

The Pacific Journal of Mathematics is published monthly. Effective with Volume 16 the price per volume (3 numbers) is $\$ 8.00$; single issues, $\$ 3.00$. Special price for current issues to individual faculty members of supporting institutions and to individual members of the American Mathematical Society: $\$ 4.00$ per volume; single issues $\$ 1.50$. Back numbers are available.

Subscriptions, orders for back numbers, and changes of address should be sent to Pacific Journal of Mathematics, 103 Highland Boulevard, Berkeley 8, California.

Printed at Kokusai Bunken Insatsusha (International Academic Printing Co., Ltd.), No. 6, 2-chome, Fujimi-cho, Chiyoda-ku, Tokyo, Japan.

\section{PUBLISHED BY PACIFIC JOURNAL OF MATHEMATICS, A NON-PROFIT CORPORATION}

The Supporting Institutions listed above contribute to the cost of publication of this Journal, but they are not owners or publishers and have no responsibility for its content or policies. 


\section{Pacific Journal of Mathematics

Vol. 19, No. $3 \quad$ July, 1966

S. J. Bernau, The spectral theorem for unbounded normal operators .......

Lu-san Chen, Asymptotic behavior of solutions of parabolic equations of

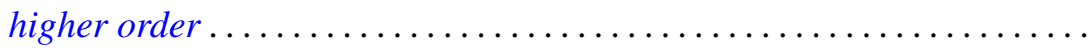

Lawrence William Conlon, An application of the Bott suspension map to the

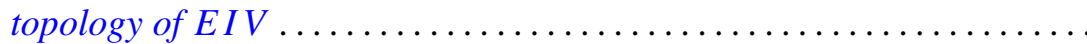

Neal Eugene Foland and John M. Marr, Sets with zero-dimensional kernels .........................................

Stanley Phillip Franklin and R. H. Sorgenfrey, Closed and image-closed

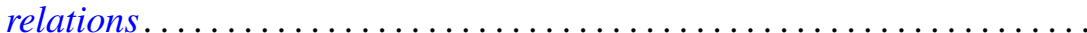

William Jesse Gray, A note on topological transformation groups with a

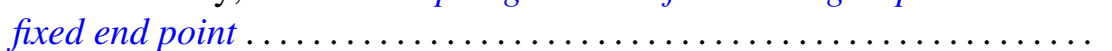

Myron Goldstein, $K$ - and L-kernels on an arbitrary Riemann surface ...... 449

George Joseph Kertz and Francis Regan, The exponential analogue of a generalized Weierstrass series .............................

Walter Leighton, On Liapunov functions with a single critical point ........ 467

Bernard Werner Levinger and Richard Steven Varga, On a problem of $O$.

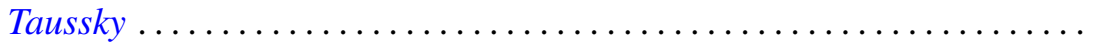

Lowell Duane Loveland, Tame subsets of spheres in $E^{3} \ldots \ldots \ldots \ldots \ldots . .489$

Erik Andrew Schreiner, Modular pairs in orthomodular lattices ......... 519

K. N. Srivastava, On dual series relations involving Laguerre polynomials ...............................

Arthur Steger, Diagonability of idempotent matrices.....

Walter Strauss, On continuity of functions with values in various Banach spaces...

Robert Vermes, On the zeros of a linear combination of polynomials ...

Elliot Carl Weinberg, On the scarcity of lattice-ordered matrix rings ....

Harold Widom, Toeplitz operators on $H_{p} \ldots \ldots \ldots \ldots \ldots$

Neal Zierler, On the lattice of closed subspaces of Hilbert space...

Irving Leonard Glicksberg, Correction to: "Maximal algebras and a theorem of Rado"

John Spurgeon Bradley, Correction to: "Adjoint quasi-differential operators of Euler type"

William Branham Jones, Erratum: "Duality and types of completeness in locally covex spaces".

Stanley P. Gudder, Erratum: "Uniqueness and existence properties of bounded observables" 